\title{
Extended Release Core Dosage Form
}

National Cancer Institute

\section{Source}

National Cancer Institute. Extended Release Core Dosage Form. NCI Thesaurus. Code C42919.

A solid or liquid core composed of active and/or inert ingredient(s) enclosed by a polymer coated shell. It is designed to release active and/or inert ingredient(s) at a controlled, prolonged rate so as to reduce dosing frequency. 